\title{
Rancang Bangun Alat Monitoring Tegangan, Arus, Daya, dan Faktor Daya Berbasis IoT
}

\author{
Amar Ma'ruf ${ }^{1}$, Rangsang Purnama ${ }^{2}$, Kunto Eko Susilo ${ }^{3}$ \\ Program Studi Sistem Komputer, Universitas Narotama \\ Jl. Arief Racman Hakim 51, Surabaya 60117 Indonesia \\ amaruf46@gmail.com ${ }^{1}, \underline{\text { rangsang.purnama@narotama.ac.id }}, \underline{\text { kunto.eko.susilo@narotama.ac.id }^{3}}$
}

Diterima : 31 Agustus 2021

Disetujui : 28 September 2021

\begin{abstract}
Di era modern energi listrik adalah suatu kebutuhan yang tidak bisa lagi dipisahkan dari kehidupan manusia. Monitoring energi listrik di lakukan dari jarak jauh menggunakan sistem berbasis IoT. Untuk mendapatkan nilai energi listrik seperti tegangan, arus, daya, dan faktor daya mengunakan sensor ZPEM-004T dan untuk monitoring jarak jauh dengan menggunakan blynk. Hasil dari uji alat berfungsi dengan benar bisa memonitoring nilai tegangan, arus, daya, dan faktor daya dari jarak jauh yang ditampilkan dimobile dengan menghasilkan tingkat error yang terjadi di tegangan +-1 , arus $+-0,001$, daya +- 0.1 dan faktor daya +-0,02. Data di atas bukan data tetap karena akan berubah dalam berapa detik baik naik atau pun turun karena energi listirk tidak ada yang stabil.
\end{abstract}

Kata kunci : Monitoring, ZPEM-004T, IoT

\section{PENDAHULUAN}

Pada kehidupan yang modern pemakaian energi listrik dalam rumah tangga, kantor, maupun industru umumnya banyak yang bersifat induktif seperti motor listrik, pompa air, kipas angin, trafo, AC, ballast lampu TL, dan lain-lain. Beban listrik yang bersifat reaktif induktif menyebabkan gelombang arus tertinggal dari gelombang tegangan, sehingga akan menyebabkan turunnya faktor daya. Penggunaan beban yang bersifat induktif akan menimbulkan daya reaktif, dimana daya reaktif yang besar akan menurunkan nilai faktor daya. Semakin besar daya reaktif semakin besar pula daya semu yang harus disuplai ke sistem.

Menurunnya kualitas faktor daya dalam suatu sistem tenaga listrik adalah sebuah masalah yang harus diminimalisir. Menurunya kualitas faktor daya akan menyebabkan kerugian contohnya bagi pemakai tenaga listrik kerugian yang didapat tegangan sistem menjadi menurun, kapasitas daya tidak dipakai secara maksimal, mengakibatkan rendahnya efisiensi tenaga listrik dan kapasitas daya yang terpasang menjadi berkurang. Sedangkan bagi penyedia layanan tenaga listrik kerugian yang didapat adalah harus mensuplai kapasitas daya yang lebih besar ke sistem.

Yulizar dkk[1], malakukan penelitian pengukuran pemakaian energi listrik pada kamar kos menggunakan mikrokontroler ATmega 328P pada Arduino UNO R3, sensor arus ACS712 untuk mendapatkan nilai arus, sensor tegangan yang dibuat dengan menggunakan alat seperti trafo stepdown, diode bridge, dan kapasitor untuk mendapatkan nilai teganan. Menghasilkan nilai arus, tegangan, daya, faktor daya, energi dan biaya pemakaian energi yang akan di tampilkan di LCD dan dikirimkan melalui SMS dengan modul GSM Shield SIM900.

Yosafat Indra Inasa $\mathrm{dkk}[2]$, melakukan penelitian alat kontrol pemakaian energi listrik pada rumah indekos menggunakan mikrokontroler ATmega 328P, sensor arus 
ACS712 untuk mendapatkan nilai arus, sensor tegangan ZMPT101 untuk mendapatkan nilai tegangan, modul GSM SIM900 sebagai penyedia informasi dan pengontrol alat dari jarak jauh melalui SMS , relay, LCD, dan keypad. Hasil pengujian alat berhasil menamilkan informasi secara jarak dekat dengan LCD dan menampilkan secara jarak jauh dengan SMS, untuk mengontrol jarak dekat dengan keypad dan untuk mengontrol jarak jauh juga bisa dengan SMS.

Salwin Anwar dkk[3], melakukan penelitian pengukuran energi listrik menggunakan mikrokontroler Arduino Mega 2560, modul PZEM-004T untuk mendapatkan nilai arus, tegangan, daya, faktor daya, frekuensi, dan energi yang akan di tampilkan di LCS 20x4. Hasil uji coba alat berfungsi dengan baik dengan nilai error arus $0,2 \%$ dan nilai error tegangan $0,2 \%$.

Muhammad Nur Arifin dkk[4], melakukan penelitian smart socket untuk smart home menggunakan mikrokontroler Wemos D1 Mini, sensor arus ACS712 untuk mendapatkan nilai arus, sensor tegangan ZMPT101B untuk mendapatkan nilai tegangan, MQTT untuk bisa dipantau dan dikendalikan dari jarak jauh. Hasil uji coba alat berjalan dengan lancar, pemantauan dan pengendalian bisa melalui web atau Android.

Dari beberapa penelitian terdahulu penelitian ini untuk memonitoring tegangan, arus, daya, dan faktor daya yang bisa dimonitoring jarak jauh menggunakan Blynk, modul PZEM-004T untuk mendapatkan nilai tegangan, arus, daya dan faktor daya, dan mikrokontroler NudeMCU ESP8266.

\section{TEORI DASAR}

\section{A. Perancanan Hardware untuk Alat Monitoring}

Untuk perancanaan hardware alat monitoring menggunakan alat modul PZEM-004T dan NudeMCU ESP8266. Modul PZEM-004T untuk sensor tegangan, arus, daya dan faktor daya. NudeMCU ESP8266 Akan menerima data dari modul PZEM-004T dan diproses yang hasilnya akan dikirim ke Blynk untuk ditampilkan diandroid.

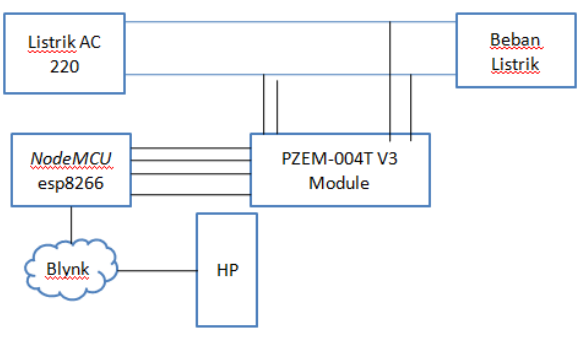

Gambar 1. Blok Diagram Alat Monitoring

\section{B. Perancangan Software Untuk Alat Monitoring}

Perancangan software adalah untuk membuat program yang bisa menggolah data dari modul PZEM-004T yang menghasilkan nilai tegangan, arus, daya dan faktor daya yang akan dikirimkan ke Blynk untuk ditampilkan.

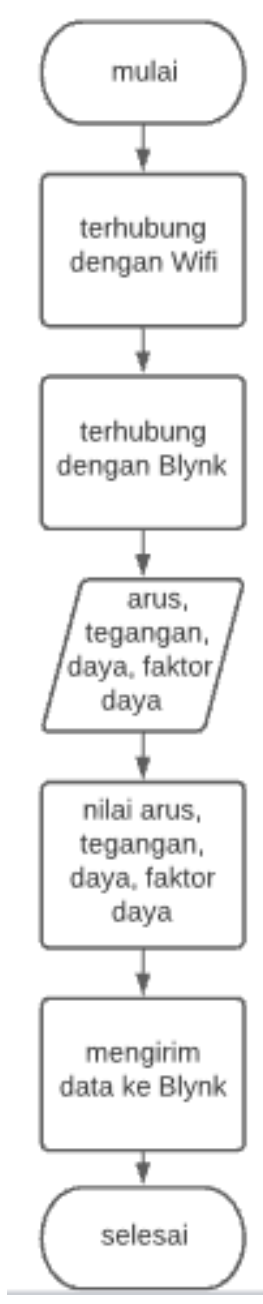

Gambar 2. Flowchat Pemrograman 


\section{Modul PZEM-004T}

Modul PZEM-004T adalah sensor yang bisa digunakan untuk menggukur tegangan rms, arus rms, dan daya aktif yang dapat dihubungkan melalui Arduino Uno, Wemos D1 Mini, NudeMCU ESP8266 ataupun platform opensource lainnya. Bentuk fisik dari papan model PZEM-004T berukuran 3,1 x 7,4 cm. modul PZEM-004T dibundel dengan kumparan trafo arus diameter $3 \mathrm{~mm}$ yang dapat digunakan untuk mengukur arus maksimal sebesar 100A. modul PZEM-004T dapat dilihat pada gambar 3 di bawah ini :

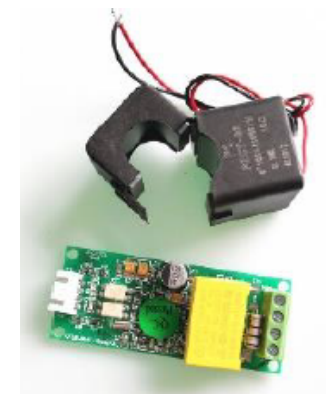

Gambar 3. Modul PZEM-004T

Modul PZEM-004T ini dapat digunakan untuk mengukur tegangan $\mathrm{AC}$, arus, daya aktif, frekuensi, faktor daya, dan eneri aktif. Modul PZEM-004T tanpa fungsi tampilan. Untuk membaca data melalui interface TTL. Interface TTL dari modul PZEM-004T ini adalah interface pasif, membutuhkan catu daya eksternal $5 \mathrm{~V}$, yang berarti ketika berkomunikasi, keempat port harus terhubung $(5 \mathrm{~V}, \mathrm{Rx}, \mathrm{Tx}, \mathrm{GND})$.[3]

\section{Blynk}

Blynk adalah sebuah layanan server yang digunakan untuk mendukung project Internet of Things (IoT). Layanan server ini memiliki lingkungan mobile user baik Android maupun iOS. Blynk Aplikasi sebagai pendukung IoT dapat diunduh melalui Google Play untuk pengguna Android dan melalui App Store bagi pengguna iOS. Blynk mendukung berbagai macam perangkat keras yang dapat digunakan untuk project IoT (Internet of Things). Blynk adalah dashborad digital dengan fasilitas antarmuka grafis dalam pembuatan projectnya.[5]

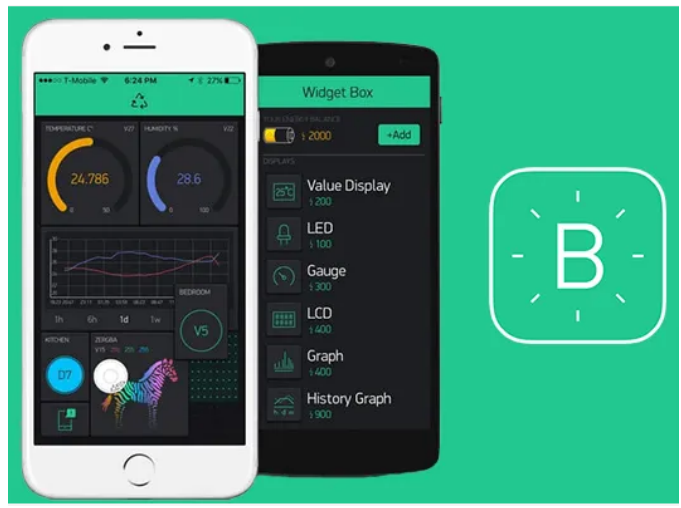

Gambar 4. Blynk

\section{E. NodeMCU ESP8266}

NodeMCU ESP8266 adalah sebuah platform IoT (Internet of Things) yang bersifat opensource. Terdiri dari perangkat keras berupa System On Chip ESP8266 dari ESP8266 buatan Espressif System, juga firmware yang digunakan, yang menggunakan bahasa pemrograman scripting lua. NodeMCU dapat dianalogikan sebagai board arduino-nya ESP8266, namun NudeMCU telah digabungkan dengan ESP8266 ke dalam sebuah board yang kompak dengan berbagai fitur layaknya mikrokontroler + kapabilitas akses terhadap Wifi juga chip komunikasi USB to serial, sehingga untuk memprogramnya hanya diperlukan ekstensi kabel data USB persis yang digunakan sebagai kabel data, kabel charging mobile Android.[5]

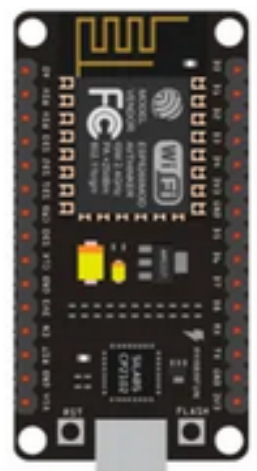

Gambar 5. NudeMCU ESP8266

\section{HASIL DAN PEMBAHASAN}

\section{A. Penyusunan Alat uji}

Alat yang digunakan untuk monitoring faktor daya adalah PZEM-004T yang bisa memperoleh 
nilai tegangan, arus, daya, dan faktor daya yang akan ditampilkan di Blynk dengan menggunakan Android.

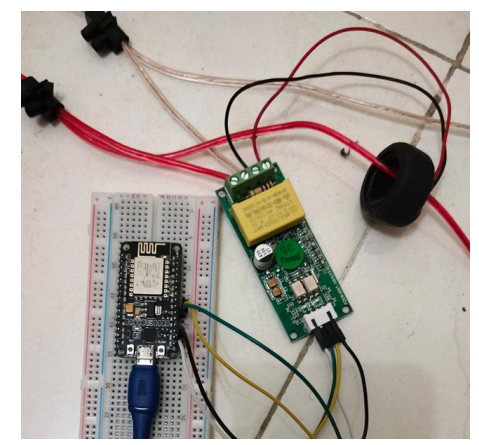

Gambar 6. NodeMcu dan ZPEM-004T

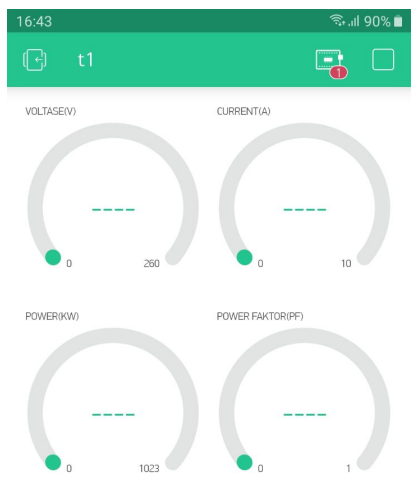

Gambar 7. Tampilan di Blynk

\section{B. Tahap Pengujian dan pembahasan}

Hasil dari pengujian alat ditampilkan sebagai berikut :

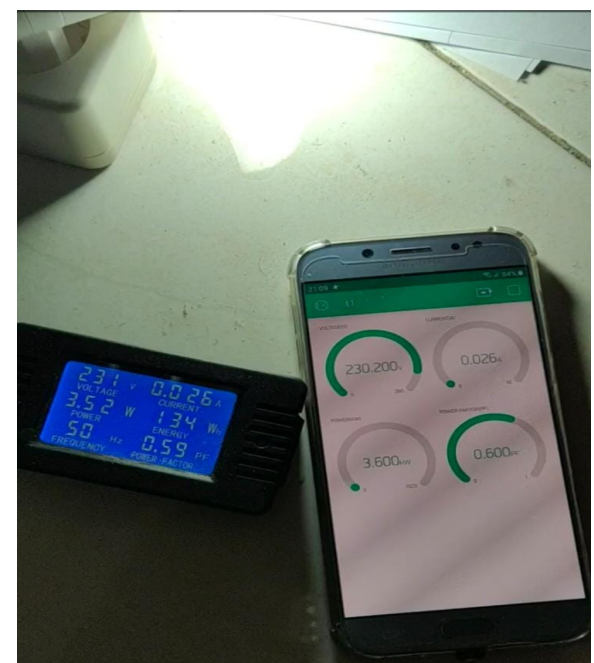

Gambar 8. Hasil Monitoring Lampu Merk Meval 3W (lampu A)
Lampu A yang digunakan dalam uji coba ini adalah lampu Merk Meval dengan daya $3 \mathrm{~W}$ yang hasilnya dapat dimonitoring dari jarak jauh dengan menggunakan Android. Nilai yang diperoleh adalah tegangan $230 \mathrm{~V}$, arus $0,026 \mathrm{~A}$, daya $3,6 \mathrm{~W}$, dan faktor daya $0,6 \mathrm{PF}$.

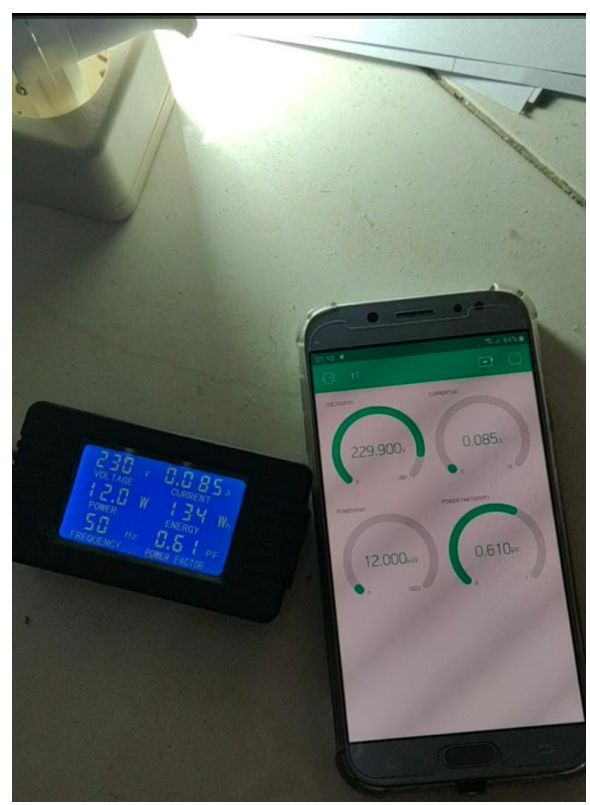

Gambar 9. Hasil Monitoring Lampu Merk Philips 12W (lampu B)

Lampu B yang digunakan dalam uji coba ini adalah lampu Merk Philips dengan daya 12W yang menghasilkan nilai tegangan $229 \mathrm{~V}$, arus $0,085 \mathrm{~A}$, daya $12 \mathrm{~W}$, dan faktor daya $0,61 \mathrm{PF}$ yang bisa dimonitoring jarak jauh dengan menggunakan Android.

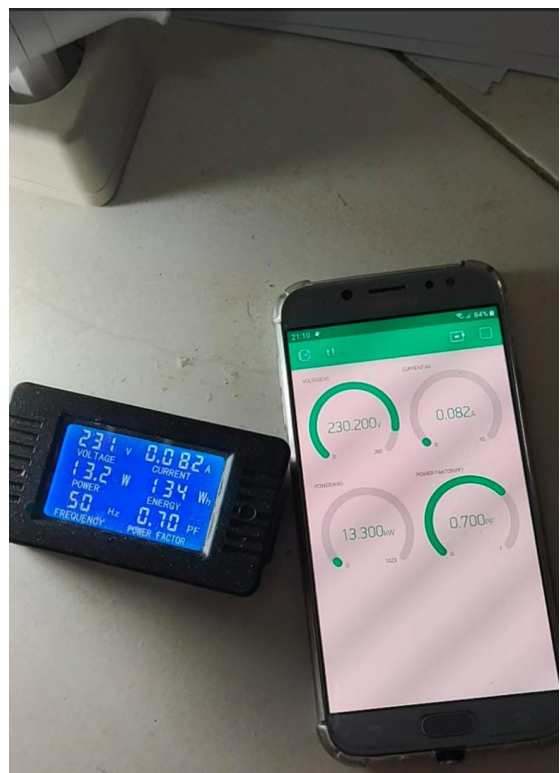

Gambar 10. Hasil Monitoring Lampu Merk Osram 13W (lampu C) 
Lampu $\mathrm{C}$ yang digunakan dalam uji coba ini adalah lampu Merk Osram dengan daya 13W yang hasilnya dapat dimonitoring dari jarak jauh dengan menggunakan Android. Nilai yang diperoleh adalah tegangan $230 \mathrm{~V}$, arus 0,082 , daya $13,3 \mathrm{~W}$ dan faktor daya $0,7 \mathrm{PF}$.

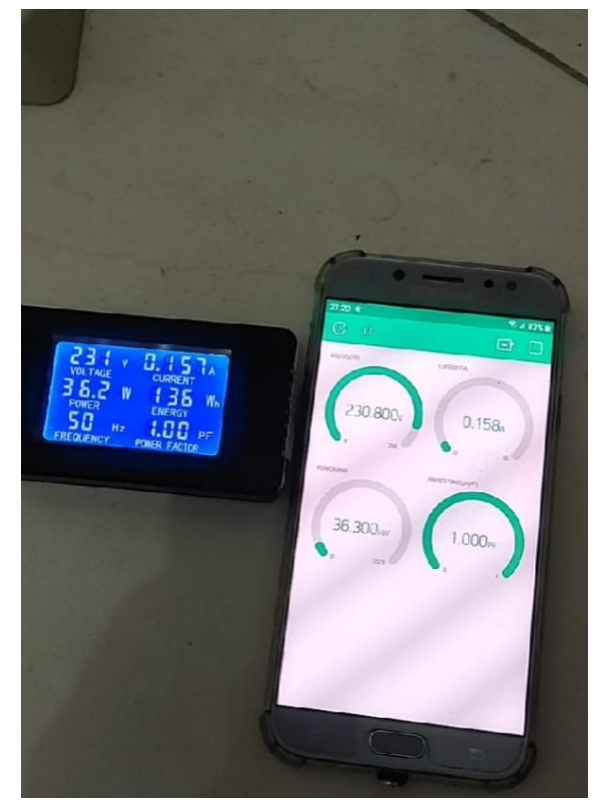

Gambar 11. Hasil Monitoring Kipas Angin

Hasil dari uji coba kipas angin adalah nilai tegangan $230 \mathrm{~V}$, arus $0,158 \mathrm{~A}$, daya $36,3 \mathrm{~W}$, dan faktor daya $1 \mathrm{PF}$ yang dapat dimonitoring jarak jauh dengan menggunakan Android.

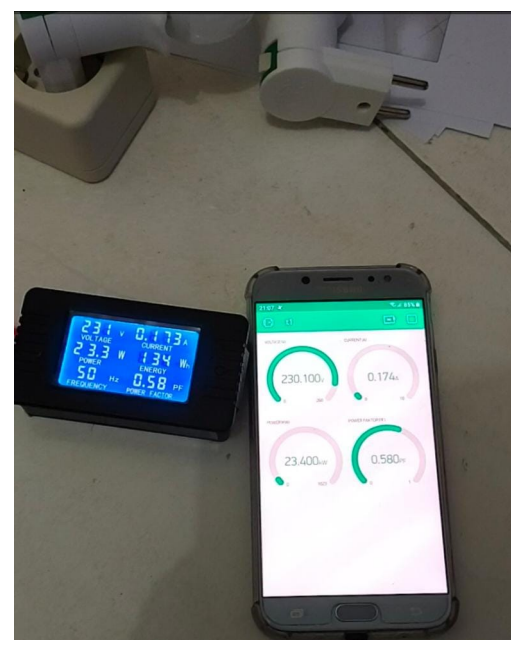

Gambar 12. Hasil Monitoring TV

Hasil uji coba TV adalah nilai tegangan $229 \mathrm{~V}$, arus $0,174 \mathrm{~A}$, daya $23,4 \mathrm{~W}$, dan faktor daya $0,58 \mathrm{PF}$ yang bisa dimonitoring jarak jauh dengan menggunakan Android.

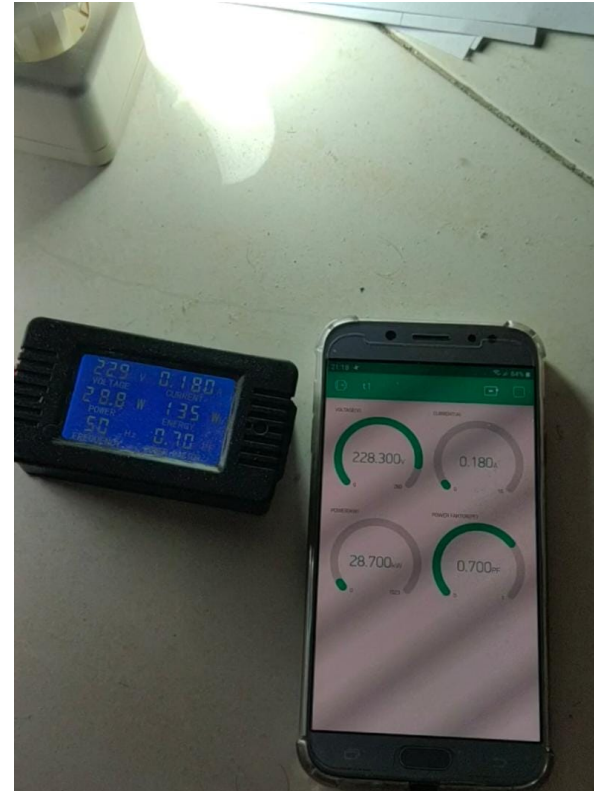

Gambar 13. Hasil Monitoring Lampu A, Lampu B dan Lampu C

Uji coba ini menggunakan lampu A, lampu B dan lampu $\mathrm{C}$ secara bersamaan menghasilkan nilai tegangan $228 \mathrm{~V}$, arus $0,180 \mathrm{~A}$, daya $28,7 \mathrm{~W}$, dan faktor daya $0,7 \mathrm{PF}$ yang bisa dimonitoring jarak jauh dengan menggunakan Andriod,

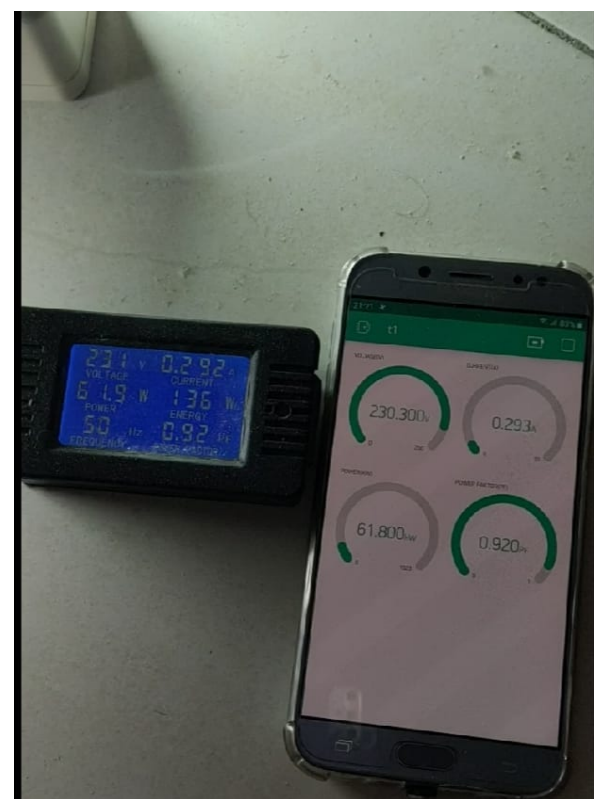

Gambar 14. Hasil Monitoring Lampu B, Lampu C dan Kipas Angin

Uji coba ini menggunakan lampu A, lampu C, dan kipas angin secara bersamaan menghasilkan nilai tegangan $230 \mathrm{~V}$, arus $0,293 \mathrm{~A}$, daya $61,8 \mathrm{~W}$, 
dan faktor daya $0,92 \mathrm{PF}$ yang bisa dimonitoring jarak jauh dengan menggunakan Android.

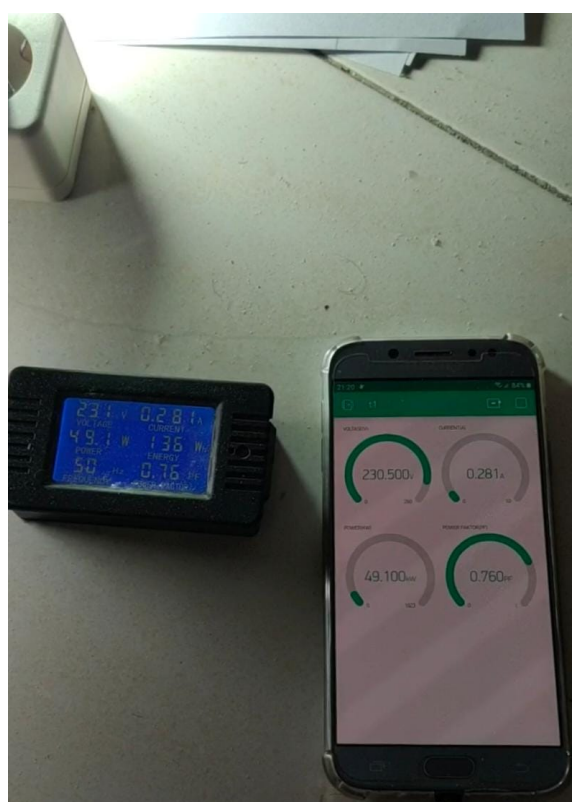

Gambar 15. Hasil Monitoring Lampu B, Lampu $\mathrm{C}$ dan TV

Uji coba ini menggunakan lampu B, lampu C, dan TV secara bersamaan menghasilkan nilai tegangan $230 \mathrm{~V}$, arus $0,281 \mathrm{~A}$, daya $49,1 \mathrm{~W}$, dan faktor daya $0,76 \mathrm{PF}$ yang bisa dimonitoring jarak jauh dengan menggunakan Android.

Tabel 1. Monitoring energi listrik

\begin{tabular}{|c|c|c|c|c|c|c|}
\hline No & Beban & Alat & \begin{tabular}{|l|} 
Tegangan \\
\end{tabular} & Arus & Daya & Faktor Daya \\
\hline \multirow[b]{2}{*}{1} & \multirow{2}{*}{$\begin{array}{l}\text { Lampu merk } \\
\text { Meval 3W } \\
\text { (lampu A) }\end{array}$} & \begin{tabular}{|l}
$\begin{array}{l}\text { Alat yang } \\
\text { dibuat }\end{array}$ \\
\end{tabular} & $230 \mathrm{~V}$ & $0,026 \mathrm{~A}$ & $3,6 \mathrm{~W}$ & $0,60 \mathrm{PF}$ \\
\hline & & \begin{tabular}{|l|} 
Alat \\
pembanding
\end{tabular} & $231 \mathrm{~V}$ & $0,026 \mathrm{~A}$ & $3,5 \mathrm{~W}$ & $0,58 \mathrm{PF}$ \\
\hline \multirow{2}{*}{2} & \multirow{2}{*}{$\begin{array}{l}\text { Lampu merk } \\
\text { Philips 12W } \\
\text { (lampu B) }\end{array}$} & \begin{tabular}{|l}
$\begin{array}{l}\text { Alat yang } \\
\text { dibuat }\end{array}$ \\
\end{tabular} & $229 \mathrm{~V}$ & $0,085 \mathrm{~A}$ & $12 \mathrm{~W}$ & $0,61 \mathrm{PF}$ \\
\hline & & $\begin{array}{l}\text { Alat } \\
\text { pembanding }\end{array}$ & $230 \mathrm{~V}$ & $0,085 \mathrm{~A}$ & $12 \mathrm{~W}$ & $0,61 \mathrm{PF}$ \\
\hline \multirow{2}{*}{3} & \multirow{2}{*}{$\begin{array}{l}\text { Lampu merk } \\
\text { Osram 13W } \\
\text { (lampu C) }\end{array}$} & $\begin{array}{l}\text { Alat yang } \\
\text { dibuat }\end{array}$ & $230 \mathrm{~V}$ & $0,082 \mathrm{~A}$ & $13,3 \mathrm{~W}$ & $0,70 \mathrm{PF}$ \\
\hline & & $\begin{array}{l}\text { Alat } \\
\text { pembanding }\end{array}$ & $231 \mathrm{~V}$ & $0,082 \mathrm{~A}$ & $13,2 \mathrm{~W}$ & $0,70 \mathrm{PF}$ \\
\hline \multirow{2}{*}{4} & \multirow{2}{*}{ Kipas angin } & \begin{tabular}{|l|}
$\begin{array}{l}\text { Alat yang } \\
\text { dibuat }\end{array}$ \\
\end{tabular} & $230 \mathrm{~V}$ & $0,158 \mathrm{~A}$ & $36,3 \mathrm{~W}$ & $1,00 \mathrm{PF}$ \\
\hline & & \begin{tabular}{|l|} 
Alat \\
pembanding
\end{tabular} & $231 \mathrm{~V}$ & $0,157 \mathrm{~A}$ & $36,2 \mathrm{~W}$ & $1,00 \mathrm{PF}$ \\
\hline \multirow{2}{*}{5} & \multirow{2}{*}{ TV } & $\begin{array}{l}\text { Alat yang } \\
\text { dibuat }\end{array}$ & $229 \mathrm{~V}$ & $0,174 \mathrm{~A}$ & $23,4 \mathrm{~W}$ & $0,59 \mathrm{PF}$ \\
\hline & & \begin{tabular}{|l|} 
Alat \\
pembanding
\end{tabular} & $230 \mathrm{~V}$ & $0,173 \mathrm{~A}$ & $23,3 \mathrm{~W}$ & $0,59 \mathrm{PF}$ \\
\hline \multirow[b]{2}{*}{6} & \multirow{2}{*}{$\begin{array}{c}\text { Lampu A, } \\
\text { lampu B, dan } \\
\text { lampu C }\end{array}$} & \begin{tabular}{|l|} 
Alat yang \\
dibuat
\end{tabular} & $228 \mathrm{~V}$ & $0,180 \mathrm{~A}$ & $28,7 \mathrm{~W}$ & $0,70 \mathrm{PF}$ \\
\hline & & \begin{tabular}{|l|} 
Alat \\
pembanding
\end{tabular} & $229 \mathrm{~V}$ & $0,180 \mathrm{~A}$ & $28,8 \mathrm{~W}$ & $0,70 \mathrm{PF}$ \\
\hline \multirow{2}{*}{7} & \multirow{2}{*}{$\begin{array}{l}\text { Lampu B, } \\
\text { lampu C dan } \\
\text { Kipas angin }\end{array}$} & $\begin{array}{l}\begin{array}{l}\text { Alat yang } \\
\text { dibuat }\end{array} \\
\end{array}$ & $230 \mathrm{~V}$ & $0,293 \mathrm{~A}$ & $61,8 \mathrm{~W}$ & $0,92 \mathrm{PF}$ \\
\hline & & \begin{tabular}{|l|} 
Alat \\
pembanding
\end{tabular} & $231 \mathrm{~V}$ & $0,292 \mathrm{~A}$ & $61,9 \mathrm{~W}$ & $0,92 \mathrm{PF}$ \\
\hline \multirow[b]{2}{*}{8} & \multirow{2}{*}{$\begin{array}{c}\text { Lampu B, } \\
\text { lampu C dan } \\
\text { TV }\end{array}$} & \begin{tabular}{|l|}
$\begin{array}{l}\text { Alat yang } \\
\text { dibuat }\end{array}$ \\
\end{tabular} & $230 \mathrm{~V}$ & $0,281 \mathrm{~A}$ & $49,1 \mathrm{~W}$ & $0,76 \mathrm{PF}$ \\
\hline & & \begin{tabular}{|l|} 
Alat \\
pembanding
\end{tabular} & $231 \mathrm{~V}$ & $0,281 \mathrm{~A}$ & $49,1 \mathrm{~W}$ & $0,76 \mathrm{PF}$ \\
\hline
\end{tabular}

Berdasarkan dari hasil uji coba bahwa alat berkerja dengan baik untuk bisa memonitoring jarak jauh yang di tampilkan oleh Blynk di
Android. Error yang terjadi di tegangan +-1 , arus +- 0,001, daya +-0.1 dan faktor daya $+-0,02$. Data di atas bukan data tetap karena akan berubah dalam beberapa detik baik naik atau pun turun karena energi listrik tidak stabil.

\section{KESIMPULAN}

Setelah melalui beberapa tahap dari perancangan, implementasi, pengujian, dan analisa hasil uji, diperoleh kesimpulan Alat monitoring energi listrik berbasis IoT yang dibuat berfungsi secara baik untuk memonitoring tegangan, arus, daya dan faktor daya secara jarak jauh yang di tampilkan oleh Blynk di Android dengan tingkat error yang terjadi di tegangan +1 , arus $+-0,001$, daya +-0.1 dan faktor daya +0,02 . Data di atas bukan data tetap karena akan berubah dalam berapa detik baik naik atau pun turun karena energi listrik tidak stabil.

\section{DAFTAR PUSTAKA}

[1] M. S. Yulizar, Ira Devi Sara, "Pada Kamar Kos Dalam Satu Hunian Berbasis Arduino Uno R3 Dan Gsm Shield Sim900,” J. Online Tek. Elektro, vol. 1, no. 3, pp. 47-56, 2016.

[2] Y. I. Indra, B. L. Pahlanop, and I. Sanubary, "Rancang Bangun Alat Kontrol Pemakaian Energi Listrik Berbasis Mikrokontroler Atmega 328P pada Rumah Indekos," Prism. Fis. Vol. 6, No. 3 (2018), Hal. 220 - 227, vol. 6, no. 3, pp. 220-227, 2018.

[3] S. Anwar, T. Artono, N. Nasrul, D. Dasrul, and A. Fadli, "Pengukuran Energi Listrik Berbasis PZEM004T," Pros. Semin. Nas. Politek. Negeri Lhokseumawe, vol. 3, no. 1, pp. 272-276, 2019.

[4] A. Mulyana and M. N. Arifin, "Smart Socket untuk Smart Home berbasis Message Queuing Telemetry Transport (MQTT)," Komputika J. Sist. Komput., vol. 8, no. 2, pp. 111-117, 2019.

[5] "Jurnal Elektrikal, Volume 6 Nomor 1, Juni 2019 , 1-10," vol. 6, pp. 1-10. 